\title{
La Política Exterior de la Unión Europea. Balance del Tratado de Lisboa en materia de Prevención de Conflictos.
}

\author{
Giorgiana Karenina Martínez Garnelo y Calvo \\ Departamento de Derecho Internacional Público y Relaciones Internacionales \\ Universidad Complutense de Madrid
}

http://dx.doi.org/10.5209/rev_NOMA.2014.v42.n2.48779

\begin{abstract}
Resumen.- Estudio que analiza el proceso que ha realizado la Unión Europea en Política de Seguridad. Tras la presentación del Tratado de Lisboa, Europa se encuentra ante nuevos mecanismos de la integración regional que suponen mayor democracia, más coherencia y visibilidad con nuevas figuras institucionales. Es en este proceso, en el cual la Prevención de Conflictos es una de las apuestas más certeras de las Unión, la cual se ve reflejada en el posicionamiento de la Unión ante organismos y naciones; es decir, una cooperación mayor entre los países que la integran. Sin embargo, el interés nacional de cada uno se magnifica con la actual crisis y el cambio orientativo en la agenda internacional sobre seguridad y defensa ponen a prueba estas nuevas transformaciones.
\end{abstract}

Palabras Clave.- Prevención de Conflictos, Agenda de Seguridad, Integración, Democracia Institucional.

\begin{abstract}
Study that examines the process that the European Union made in Security Policy matter. After the presentation of The Lisbon Treaty, Europe faces new mechanisms of the regional integration that posed more democracy and greater coherence and institutional visibility. Is in this process in which the Conflict Prevention is one of the most certain bets of the Union, which is reflected in the position of Europe in organizations and nations; this means, a greater cooperation between countries in the European Union. However, the nacional interest of each country is magnified by the crisis and the guidance change on the security and international defense agenda test these new transformations.
\end{abstract}

Keywords.- Conflict Prevention, Security Agenda, Integration, Institucional democracy.

\section{Introducción}

A 50 años de la génesis en la Integración Europea, las comunidades registran un periodo sin guerras, de estabilidad y de avances, sobre todo en materia constitutiva y jurídica. La Unión Europea como referente en prevención de conflictos sigue siendo una parte fundamental a nivel internacional en este ámbito.

La prevención de conflictos en la Unión Europea se remonta al Tratado de Ámsterdam en 1997, en el que se señalaba la creación de las misiones Petersberg y su respuesta rápida, para 1999 en Helsinki, la PESD pasaba a gestionar crisis civiles y militares, cuyo principal objetivo era militar. En Feira, año 2000, se fortalecieron las capacidades civiles y se creo el comité para la gestión de crisis civiles. En el año 2011 en Gotemburgo y Niza, la Unión dio un vuelvo en prevención de conflictos, ya que se había creado el primer programa de la Unión Europea para la prevención. Finalmente en 2004 se llevo a cabo el 
Plan de Acción Civil que tenía como objetivo no necesariamente prevenir, sino también actuar post-conflicto.

Fernando Luengo apunta; «hay diferencias entre la Europa posible y la Europa que queremos», es un encuentro trascendental por la época que nos ha tocado vivir y la pluralidad de opiniones así como el papel de Europa frente a la crisis, el balance se tiene que hacer con las diversas miradas de todos los que conforman la Unión. ${ }^{1}$ Europa ha atravesado diversas etapas desde su creación y hoy sabemos que en el Consejo Europeo de $\mathrm{Niza}^{2}$ en el año 2000, surgió una política que modificó la forma de abordar las políticas de prevención de conflictos en la Unión, en él se especifico su relación principal con la OSCE, OTAN y el Consejo de Europa.

La Unión Europea se basa en el principio democrático y en la pluralidad de Instituciones que hoy sustentan los mecanismos e instrumentos para la prevención de conflictos, Carlos Carnero señalaba que Lisboa es un Tratado que ha dado un gran salto cualitativo, sin embargo hace falta uno nuevo que termine formalizando la Unión política europea, pese a ello se debe defender y recuperar el orgullo de ser europeo, pues Europa ha vuelto para quedarse. ${ }^{3}$ Esto supone que la crisis, es un catalizador que exige más Europa, una integración más fuerte y consolidada.

«La participación de los ciudadanos en la toma de decisiones es imprescindible para la democracia», afirma Margot Wallström, Vicepresidenta de la Comisión Europea, responsable de Relaciones Institucionales y Estrategia de la Comunicación. «El Tratado de Lisboa proporcionará a los ciudadanos los instrumentos necesarios para expresar su opinión e influir directamente en el proceso legislativo de la UE.» ${ }^{4}$

Por todo lo anterior señalado, la Unión Europea sigue siendo después de los Estados Unidos el motor principal de aportaciones monetarias en materia de prevención de conflictos; por ejemplo, para operaciones de mantenimiento de la paz de Naciones Unidas o "UN peacekeeping operations" en inglés, siguen siendo Alemania, Inglaterra, Francia, Italia, España y Holanda. ${ }^{5}$ Lo que significa que la prevención de conflictos continúa en uno de los asientos de mayor importancia en la contabilidad de Europa.

\footnotetext{
${ }^{1}$ (2009) LUENGO, Fernando, Encuentro Internacional Complutense. Ciencia y Sociedad. "El papel de Europa en el Escenario Internacional: Visiones desde los países del Centro y Este del Continente", organizado por el Instituto Complutense de Estudios Internacionales, el 25 y 26 de Marzo.

${ }^{2}$ Consejo Europeo de Niza, texto completo en: http://www.europarl.europa.eu/summits/nice1 es.htm\#III

${ }^{3}$ (2010) CARNERO, Carlos, Congreso, "Los grandes retos de la Presidencia Española", 24 de Febrero. Madrid, España.

${ }^{4}$ Consulta pública sobre la Iniciativa Ciudadana Europea.

Disponible en:

http://ec.europa.eu/dgs/secretariat general/citizens initiative/index es.htm

${ }^{5}$ Los 15 principales países que aportan un presupuesto importante a Naciones Unidas. Global Policy Forum, obtenido de United Nations: 2008 Status of Contributions to the Regular Budget, International Tribunals, Peacekeeping Operations and Capital Master Plan.
} 
Pese a grandes esfuerzos de la Unión por mantener la coherencia y visibilidad en su Política Exterior, como el nombramiento de la Alta Representante para Política Exterior y Seguridad Común, Europa sigue careciendo de fortaleza para enfrentar las posiciones individuales de cada uno de los países miembros.

\section{1.- Una Europa más democrática tras la entrada del Tratado de Lisboa. Avances significativos.}

Las novedades en lo que a democracia representativa y participativa se refiere son muy notables, a partir de ahora el Parlamento europeo tiene un papel más determinante en los procesos decisorios, pasando a ser la codecisión el procedimiento ordinario para la toma de decisiones entre Consejo y Parlamento. La ciudadanía europea se ha posicionado de forma más firme tras la entrada en vigor del Tratado de Lisboa con la introducción, entre otros, de mecanismos de consulta previa, como la Iniciativa Ciudadana Europea (ICE) y con obligatoriedad jurídica de la Carta de Derechos Fundamentales de la Unión Europea, parece existir un giro en la Unión. No obstante lo regional y nacional ganan posiciones con el nuevo papel de los Parlamentos nacionales y regionales, y las entidades locales pugnan porque su voz sea escuchada.

El avance democrático desde la introducción de procedimientos de "alerta rápida" y de diálogo político de la Comisión con los Parlamentos nacionales y de estos con el Parlamento Europeo son innegables y se parte de este punto para ejemplificar quizá ahora la parte contradictoria de Lisboa. Es innegable que el Tratado reforma el entramado institucional de la UE, dando más peso al Parlamento Europeo, al pasar a ser la codecisión con el Consejo el procedimiento ordinario; e inserta nuevos cauces de diálogo con los entes nacionales y regionales. Asimismo, el Consejo Europeo pasa a ser una institución comunitaria más, con las garantías jurídicas que esto implica, y la Comisión da pequeños pasos, pero al fin y al cabo, avances, en la senda democratizadora.

Son estos elementos, los indispensables para hablar de "más democracia" ya que la institución que, sin duda sale más reforzada tras el Tratado de Lisboa es el Parlamento Europeo, la institución en la que están representados de forma directa los ciudadanos europeos. Según Gregorio Garzón Clariana, esta ha sido percibida como una "novedad muy importante par a la credibilidad democrática de la construcción europea"6

Esta es una nueva experiencia del continente europeo, siempre caracterizado por continúas crisis, desavenencias, revoluciones y guerras; una democracia que siempre ha sido amenazada constantemente por enemigos. Para entender las características propias del proceso democrático de la Unión tenemos que tener en cuenta las particularidades de los elementos de democratización

\footnotetext{
${ }^{6}$ (2009) GARZÓN CLARIANA, Gregorio "Democracia y Estado de Derecho en la puesta en marcha del Tratado de Lisboa", en Francisco Aldecoa Luzárraga, Luis Norberto González Alonso y Mónica Guzmán Zapater (eds.): La presidencia española de la Unión Europea en 2010 : propuestas para una agenda ambiciosa, Madrid, Asociación Española de Profesores de Derecho Internacional y Relaciones Internacionales, pp. 33-44.
} 
europeos: 1) la identidad europea 2) la opinión pública europea, 3) la ciudadanía europea y sus posibilidades de desarrollo y, finalmente, 4) los inicios de una sociedad civil europea. ${ }^{7}$

En este sentido, centrarnos en la repercusión de lo que la democracia significa en prevención se conflictos es inminente. Por un lado y como ya se ha expuesto con anterioridad, nos encontramos ante una encrucijada, por un lado "mayor coherencia y visibilidad" y por el otro, tratar de resolver conflictos de acuerdo a intereses nacionales. Que significa esto, que es verdad que la Unión Europea magnifica su posición y centra su papel en un solo debate, pero hasta cierto punto, ya que hemos visto incluso problemas a la hora de catalogar por ejemplo el conflicto extendido de la Primavera árabe, sobre quién debe decidir que, en este sentido, nos referimos a Francia o Alemania.

La capacidad de los parlamentos nacionales por tener más ingerencia o "participar" en asuntos de la Unión Europea, también es una respuesta directa, que responde a los intereses de un país, pero que por otro lado, estructura respuestas preventivas y de resolución de conflictos, como la separación de posiciones de los países de la Unión Europea para refrendar el surgimiento de Sudan del Sur o aquellos que no lo reconocían.

El texto sigue ofreciendo garantías a las dos legitimidades de la Unión Europea: ciudadanos y Estados. Por un lado, la obligatoriedad jurídica de la Carta de Derechos Fundamentales protege a los primeros frente al poder público europeo y el incremento de la supervisión de los Parlamentos Nacionales que tiene también la función garantista de "evitar la extralimitación en las competencias europeas por parte de las instituciones comunes". ${ }^{8}$ Un importante paso para todos los países europeos que pensaban que Europa se extralimitaba en materia de presupuesto destinado a la prevención de conflictos. Ahora se podrá opinar desde el interior de cada país, incluyendo por supuesto mil firmas de ciudadanos para tratar de aceptar $u$ oponerse a una política de la Unión.

Como uno de los ejes rectores, la democracia ha sido elegida siempre como requisito necesario para ser miembro de la Unión Europea y es el que siempre veremos de la mano del Informe Birkelbach ${ }^{9}$. El funcionamiento democrático de la Unión se basa en un Sistema Institucional y de división de poderes, así como en la participación de los Parlamentos Nacionales y de la sociedad civil, aunado a el principio democrático en la Política Exterior.

\footnotetext{
${ }^{7}$ (2005) KAELBLE, Hartmut: Caminos hacia la democracia los déficit democráticos de la Unión Europea, Biblioteca nueva, Madrid.

${ }^{8}$ (2008) GUINEA LLORENTE, Mercedes: "De Roma I a Roma II: la aportación del Tratado Constitución al modelo político de la integración europea", en Francisco Aldecoa Luzárraga, José Manuel Sobrino Heredia, Luis Norberto González Alonso, Antonio Pastor Palomar, Joaquim Forner y Mónica Herranz Ballesteros (Coords.): Los tratados de roma en su cincuenta aniversario, Marcial Pons, Madrid, pp.43- 70.

920 años de España en la Unión Europea, Ministerio de Asuntos Exteriores y Cooperación.http://www.maec.es/es/menuppal/espanayue/EspanaenEuropa/Paginas/etxespan aeuropa.aspx
} 
En este sentido, el Tratado de Reforma de los tratados existentes, firmado en la capital portuguesa, es, según José María Gil Robles, un ejercicio de "disimulo" consistente en reproducir la mayoría de los cambios previstos por el proyecto de Constitución suprimiendo la "música constituyente y repartiendo la letra entre dos tratados ya existentes. ${ }^{10}$ El modelo de la UE tras el Tratado de Lisboa da pasos hacia una mayor democratización al complementar lo representativo con el principio de participación de la sociedad civil.

El denominado "soft power" de la Unión, es decir, su extremamente débil capacidad represiva, o más bien, gran descentralización, hace que los Estados miembros sean finalmente los encargados de sofocar movimientos subversivos. Entonces, con bajos costes de redistribución sumados a los altos costes represivos, la élite no tendría la motivación suficiente para sofocar las fuertes demandas sociales para la democratización de la Unión. Así pues, una de las principales críticas que se le hace es la excesiva "domesticación" de las políticas de la UE, la mayor visibilidad de la Europa a varias velocidades. Aunque, por otro lado hay que tener en cuenta que estas protestas suelen ir acompañadas de llamamientos a la protección de los intereses nacionales más que a una verdadera Integración.

Pero todos estos reproches que se le achacan a la política comunitaria (debilidad, excesivo estatalismo, y orientación anti-integracionista) apuntan a problemas estructurales más profundos de la democratización europea. Es decir, algunos autores como el propio Schimmelfenning, defienden la no existencia de un demos ${ }^{11}$ europeo, situación que impide la democratización de la $\mathrm{UE}^{12}$. Para que exista un verdadero pueblo europeo, indica Schimmelfenning, éste se debe identificar entre sí como miembro de una única comunidad política, y necesita ser capaz de tomar acciones políticas efectivas

\section{2.- La Prevención de Conflictos como prioridad europea pre y pos Lisboa.}

Los objetivos de la Unión en materia de Seguridad, siempre se han caracterizado por «el fortalecimiento de la seguridad de la Unión en todas sus formas» y «el mantenimiento de la paz y el fortalecimiento de la seguridad internacional, de conformidad con los principios de la Carta de las Naciones Unidas».

El Tratado de Lisboa, también constituye importantes modificaciones, como el hecho de que la Unión goce formalmente de personalidad jurídica.

\footnotetext{
${ }^{10}$ (2007) GIL-ROBLES DELGADO, José María: "Tratado de Lisboa: Un paso adelante en la evolución del sistema institucional europeo, Revista de las Cortes Generales", Madrid, España. pp. 10-37.

Estos dos son el Tratado de la Unión (que conservará su nombre) y el Tratado de la Comunidad Económica Europea o Tratado de Roma, que pasará a llamarse "Tratado de Funcionamiento", y un tercero, la Carta de Derechos Fundamentales, la parte II de la Constitución que queda independiente y con valor de tratado.

${ }^{11}$ Pueblo, de raíz griega

${ }^{12}$ (2009) SCHIMMELFENNING Frank, The Normative Origins of Democracy in the European Union: Towards a Transformationalist Theory of Democratization (Los orígenes normativos de la democracia en la Unión Europea: transformación de la Teoría de la Democratización), Challenges to Democracy in the 21st Century. Zurich.
} 
Posiblemente de aquello que se plantea como la eficacia y rapidez de la Unión, sea de lo que más carece. Indudablemente con el Tratado se mantiene la unanimidad como regla general del Consejo en materia de Política Exterior y Seguridad Común (PESC). ${ }^{13}$

La elección por parte de la Unión Europea de asignar a un Alto Representante para los Asuntos Exteriores y de Política de Seguridad que a su vez será vicepresidente de la Comisión es sin duda una decisión acertada. La laborista británica Catherine Ashton, considerada persona "gris" en el panorama europeo, ha pretendido conciliar posiciones en materia de prevención de conflictos, sin embargo, el resultado a sido decepcionante. La inadecuada proyección internacional de la Unión ha dejado entre ver que indudablemente hay posiciones distantes en materia de Política Exterior entre los países de la Unión.

Reino Unido no se ha visto muy involucrado en invertir o democratizar más a la Unión, sin embargo cada día se trata de dar un nuevo impulso a la Política Exterior. Ahora bien, la organización y el funcionamiento del Servicio Exterior ya demorado, solo ha sido muestra del impulso político obtenido por medio del Comité Político y de Seguridad (COPS). ${ }^{14}$

Como bien se ha mencionado anteriormente y como ejemplificación, Alemania, Reino Unido, Francia, Italia, España y Holanda son los principales países que aportan dinero para las operaciones de mantenimiento de la paz en Naciones Unidas, no necesariamente en operaciones que se realicen por parte de la Unión Europea. El siguiente cuadro así lo demuestra.

Debt of 15 Largest Payers to the Peacekeeping Budget: 2008 (in US\$ Million)

\begin{tabular}{|c|c|c|c|c|c|c|c|c|c|c|c|c|}
\hline \multirow[b]{2}{*}{ COUNTRY } & \multicolumn{3}{|c|}{ September } & \multicolumn{3}{|c|}{ October } & \multicolumn{3}{|c|}{ November } & \multicolumn{3}{|c|}{ December } \\
\hline & $\begin{array}{c}\text { Current } \\
\text { Debt }\end{array}$ & Prior Debt & $\begin{array}{l}\text { Total } \\
\text { Debt }\end{array}$ & $\begin{array}{l}\text { Current } \\
\text { Debt }\end{array}$ & Prior Debt & $\begin{array}{l}\text { Total } \\
\text { Debt }\end{array}$ & $\begin{array}{c}\text { Current } \\
\text { Debt }\end{array}$ & Prior Debt & $\begin{array}{l}\text { Total } \\
\text { Debt }\end{array}$ & $\begin{array}{c}\text { Current } \\
\text { Debt }\end{array}$ & Prior Debt & $\begin{array}{l}\text { Total } \\
\text { Debt }\end{array}$ \\
\hline US & 1,153 & 461 & 1,614 & 784 & 377 & 1,161 & 661 & 377 & 1,038 & 524 & 336 & 860 \\
\hline Japan & 878 & 46 & 924 & 1,050 & 46 & 1,096 & 1,050 & 46 & 1,096 & 1,050 & 46 & 1,096 \\
\hline Germany & 48 & - & 48 & 89 & - & 89 & - & - & - & - & - & - \\
\hline UK & 44 & - & & 125 & - & 125 & 81 & - & 81 & 81 & - & 81 \\
\hline France & 213 & - & 213 & 180 & - & 180 & 141 & - & 141 & 80 & - & 80 \\
\hline Italy & 81 & - & 81 & 81 & - & 81 & 53 & - & 53 & - & - & - \\
\hline Canada & 17 & - & 17 & 31 & - & 31 & - & & - & - & - & - \\
\hline Spain & 185 & 9 & 194 & 216 & 9 & 225 & 216 & 9 & 216 & 216 & 9 & 225 \\
\hline China & 179 & 3 & 182 & 108 & 1,459 & 1,567 & 108 & 1 & 109 & 43 & 1 & 44 \\
\hline Mexico & 16 & - & 16 & 6 & - & 6 & 6 & - & 6 & 6 & - & 6 \\
\hline $\begin{array}{c}\text { Republic of } \\
\text { Korea }\end{array}$ & 52 & & 52 & 74 & - & 74 & 74 & - & 74 & 69 & - & 69 \\
\hline Netherlands & 32 & - & 32 & 22 & - & 22 & 2 & - & 2 & 2 & - & 2 \\
\hline Australia & 10 & - & 10 & 18 & - & 18 & - & - & - & - & - & - \\
\hline Switzerland & 19 & - & 19 & 32 & - & 32 & 32 & - & 32 & - & - & - \\
\hline $\begin{array}{c}\text { Russian } \\
\text { Federation }\end{array}$ & 30 & & 30 & 23 & - & 23 & 15 & - & 15 & 15 & - & 15 \\
\hline
\end{tabular}

${ }^{13}$ (2010) DE AYALA, José Enrique, Política Exterior, "Lisboa por fin. El tratado abre una nueva era en la UE", $n^{\circ} 133$, enero/febrero.

${ }^{14}$ (2009) FERNÁNDEZ-ARIAS, Carlos, Política Exterior, Hacia una diplomacia común. EI Servicio Europeo de Acción Exterior, $n^{\circ}$ 133, enero/febrero. 
Fuente: United Nations: 2008 Status of Contributions to the Regular Budget, International Tribunals, Peacekeeping Operations and Capital Master Plan.

La Unión Europea siempre se ha comprometido con Naciones Unidas, mediante la aportación de tropas, agentes de policía y observadores a las operaciones de las Naciones Unidas, hasta un total de 3259 efectivos, es decir, el 9 \% del personal total de las Naciones Unidas en junio de 2003.

Por ejemplo, la Unión ha estado presente en las grandes operaciones de mantenimiento de la paz en los Balcanes: la Fuerza Multinacional de Estabilización (SFOR), que operaba en Bosnia y Herzegovina, y la Fuerza Multinacional de Seguridad en Kosovo (KFOR), en conexión con la Misión de Administración Provisional de las Naciones Unidas en Kosovo (UNMIK). La aportación de tropas de los Estados miembros de la UE a estas operaciones representa aproximadamente el $60 \%$ del total. En África, más de 20000 efectivos procedentes de los Estados miembros de la Unión Europea servían bajo mandato de las Naciones Unidas en abril de 2003.

Las capacidades civiles y militares de la Unión son sumamente importantes, ya que representa gran apoyo a Naciones Unidas. En el Consejo Europeo de Helsinki de diciembre de 1999 se estableció uno de los objetivos: una capacidad militar de 50000 a 60000 efectivos, con el apoyo de los recursos aéreos y navales.

Respecto a las capacidades civiles, la policía mantenía la disponibilidad de hasta 5000 agentes, 1400 de los cuales podrán desplegarse en menos de mes y en fortalecimiento del Estado de Derecho. La disponibilidad se centra en aproximadamente 300 fiscales, jueces y funcionarios de prisiones para reforzar la labor de los cuerpos de policía en las situaciones de crisis. ${ }^{15}$

En prevención de conflictos, el nuevo papel de los Parlamentos Nacionales ha sido decisivo en el Tratado de Lisboa, ya que el TUE mejora estos preceptos, introduciendo, entre otros, un procedimiento de alerta rápida para garantizar que los Parlamentos Nacionales pueden pronunciarse y decir si los proyectos de ley afectan al principio de subsidiariedad. Así, por un lado, establecen la obligatoriedad de que la Comisión informe a los Parlamento nacionales de cuantos documentos consulta ${ }^{16}$ (libros verdes, blancos y comunicaciones) y sobre su programa legislativo anual, y por otro, regula el control legislativo, estableciendo que las propuestas de actos legislativos se transmitirán, además de al Parlamento Europeo y al Consejo, a los Parlamentos Nacionales. Esta última tiene la finalidad de verificar, por parte de estos, que la normativa cumple con el requisito de subsidiariedad, que analizamos con más detenimiento a continuación.

\footnotetext{
${ }^{15}$ (2004) La Unión Europea en ampliación y las Naciones Unidas: Hacer que el multilateralismo importe. Publicado por la Unión Europea aprobado por la TROIKA y los Estados Miembros en Nueva York - Capítulo 5.

${ }^{16}$ (2010) GUTIERREZ ESPADA, Cesáreo y CERVELL HORTAL, María José, La adaptación al Tratado de Lisboa (2007) del sistema institucional decisorio de la UE, su acción exterior y su personalidad jurídica, Editorial Comares, Murcia. España.
} 
Esto quiere decir que antes de que la Unión se decante por una opción u otra para participar en conflictos internacionales, cada país podrá decidir si afecta 0 no a los intereses del mismo. En este sentido los parlamentos decidirán si la Unión no se excede y cumple con la subsidiariedad establecida, dicho de otra manera los países se pueden poner de acuerdo para ir o no a un conflicto. Esto se traduce en retraso de actuación pero que hace cumplir con el objetivo de transparencia que la Unión debe conseguir.

El artículo 5.3 del TUE reconoce por primera vez la aplicación del principio de subsidiariedad también a nivel regional y local, y el artículo 2 del Protocolo sobre aplicación de los principios de subsidiariedad y proporcionalidad, recoge la obligación de la Comisión de "consultar a las regiones y colectividades locales antes de formular una propuesta legislativa". La práctica en la gobernanza europea de consulta a nivel regional y local se eleva así, al más alto nivel.

El Consejo Europeo de Gotemburgo de 2001 marcó un nuevo arranque político en el que la Unión Europea hiciera de la prevención de conflictos un objetivo esencial de sus relaciones exteriores. La prevención de conflictos no sólo debe integrarse en el plano de las políticas y en los acuerdos celebrados con terceros países, sino que ha de aplicarse e incluirse en todas las políticas y actividades externas, incluidas la Política Europea de Seguridad y Defensa (PESD), la cooperación al desarrollo y el comercio exterior como subrayan Francisco Aldecoa y Mercedes Guinea, el Tratado de Lisboa supone un avance en lo que se refiere a dotar a las regiones europeas de instrumentos para defender sus competencias de la intromisión que pueden realizar las instituciones europeas. ${ }^{17}$

El mecanismo de alerta rápida o temprana es sin duda una novedad en el Tratado, da la posibilidad de bloquear o modificar una iniciativa de ley comunitaria que un número significativo de parlamentos nacionales considera que vulnera el principio de subsidiariedad y proporcionalidad, en definitiva sacar tarjeta a la Comisión Europea cuando se exceda en sus funciones. Esta medida permite el control político por parte de los parlamentos nacionales de dichos principios, y constituye un mecanismo original ya que asocia por primera vez a los parlamentos nacionales de forma directa en el proceso decisorio.

El mandato del Consejo Europeo de Bruselas de junio de 2007 precisaba que "los Parlamentos nacionales tendrán una función aún mayor", acordándose dicho objetivo en la introducción de una disposición de carácter general en la que recopilaba la función de estas cámaras en la UE, y en la creación de un "mecanismo reforzado de control de subsidiariedad".

Es importante resaltar que este control del principio de subsidiariedad se lleva a cabo con anterioridad a la adopción de la decisión por parte de los Parlamentos nacionales (ex ante, control político), sin que por ello se ponga en cuestión la posibilidad de acudir ante el Tribunal de Justicia de las Comunidades Europeas (TJCE) para que soluciones una diferencia de posturas entre los Parlamentos

${ }_{17}$ (2010) ALDECOA LUZÁRRAGA, Francisco y GUINEA LLORENTE, Mercedes: "La Europa que viene: El Tratado de Lisboa", Marcial Pons, Madrid. España. 
nacionales y las instituciones de la UE (ex post, control judicial). Así, esta primera fase permite que cualquier dictamen motivado adoptado por una cámara o Parlamento nacional, deberá ser "tomado en cuenta" por la Comisión y el resto de las instituciones.

Sin embargo, no es suficiente que el Parlamento de un Estado miembro de la negativa a una iniciativa legislativa planteada por las instituciones comunitarias. Es preciso que al menos un tercio del total de votos que se les atribuye a las cámaras nacionales, coincida en valorarla de forma negativa, o un cuarto en asuntos del espacio de libertad, seguridad y justicia para que "vuelva a estudiar la propuesta". Una vez superado este umbral la institución de la que emanó el proyecto tiene tres opciones: rechazo, modificación o mantenimiento.

El Tratado de Lisboa mejora los instrumentos ya existentes para la PESD: se amplían las misiones (artículos 42.1 y 43); se permite que una misión de la Unión se encargue a un Estado miembro o grupo de Estados miembros (artículo 44); se simplifican los procedimientos de financiación (artículo 41, no lo suficiente en el caso de operaciones militares), así mismo incorpora innovaciones importantes en la defensa. La Unión Europea se convierte en una alianza de defensa colectiva entre los Estados miembros (artículo 42.7): «Si un Estado miembro es objeto de una agresión armada en su territorio, los demás Estados miembros le deberán ayuda y asistencia con todos los medios a su alcance, de conformidad con el artículo 51 de la Carta de Naciones Unidas». La OTAN sigue siendo parte esencial de este apartado, ya que es el motivo del que se extrae casi calcado un artículo de la Organización, que es la defensa mutua.

Se incorpora también a este Tratado una cláusula de solidaridad entre Estados miembros, para prevenir y reaccionar ante ataques terroristas o catástrofes (artículo 222 del Tratado de Funcionamiento de la Unión Europea). Esta cláusula no pertenece estrictamente a la defensa pero junto con la alianza defensiva proporciona a los Estados miembros una asistencia completa. Claramente influenciada por los atentados del 11 de septiembre de 2001 y 11 de marzo de 2004, esta cláusula es también automática.

La respuesta europea integral y solidaria, no sólo a los conflictos armados del futuro que cambian sus características, sino a otras muy diferentes amenazas y riesgos, deben tener las siguientes características:

a) Expedicionarias y sostenibles. Capaces de actuar de forma autosuficiente en operaciones que podrán desarrollarse en áreas geográficas alejadas del territorio europeo adonde deberán desplazarse de forma rápida y ser capaces de actuar por largos periodos de tiempo, lo que implica que su funcionamiento sea más costoso.

b) Interoperables. Con capacidad plena para la actuación conjunta y combinada. En unidades más pequeñas y numerosas, con disponibilidad y flexibilidad para constituir las estructuras operativas más adecuadas y eficaces para actuar en todo el espectro de las operaciones, desde las de ayuda humanitaria hasta las de combate más exigentes. 
d) Tecnológicamente avanzadas. Organizadas y adiestradas para emplear las tecnologías más modernas y para operar en red, integrando las redes de información con las de mando, control e información y las herramientas de gestión para facilitar la agilidad en el proceso de toma de decisiones y la eficacia en las operaciones.

e) Eficientes orgánica y logísticamente. Combinando adecuadamente operatividad y tradición, y garantizando un apoyo logístico flexible y seguro con el mejor ratio coste-eficacia.

f) Profesionales y motivadas. Enraizadas y apoyadas por la sociedad civil, por su alto nivel de preparación y su satisfacción por los resultados de su labor.

La Agencia Europea de Defensa también interviene ordenando y armonizando los requisitos expresados por los Estados miembros para sus nuevos equipos y sistemas, para lo que la coordinación es indispensable junto a las estructuras militares de la Unión Europea en el comité militar. Los Battle gropus, también fueron motivación para un cambio en Lisboa,.

La propuesta sobre battlegroups fue oficialmente presentada al Consejo Europeo en marzo de 2004. El secretario general Javier Solana propuso, en su informe sobre respuesta rápida del 22 de abril, un plan para desarrollar las capacidades requeridas y en mayo del mismo año el Consejo de Ministros aprobaba la propuesta y la integraba como parte del Objetivo Global 2010, quedando pendiente el desarrollo conceptual. Al mismo tiempo, se señaló el 1 de enero de 2007, como fecha en que los Battlegroups deberían alcanzar su Capacidad Operativa Plena (FOC). ${ }^{18}$

Los Battlegroups cuentan con un máximo de diez días desde el momento en que el Consejo adopte la decisión de lanzar la operación y así iniciar el despliegue en el teatro de operaciones; son fundamentales dentro de las fuerzas de la Unión.

Sobre lo anterior expuesto, a continuación se señalan las misiones en las que ha participado la Unión, tanto civiles y militares en el siguiente cuadro, destacando el nombre de la misión, el lugar donde se desempeñan o se han desempeñado, el coste y el número de personas que participan en ellas. Las misiones representan un esfuerzo de Europa por participar en los conflictos internacionales dando apoyo a países como el Congo principalmente y Bosnia y Herzegovina. ${ }^{18}$ (2007) Posibles escenarios de actuación de los Battlegroups de la Unión Europea. Centro
Superior de Estudios de la Defensa Nacional. Ministerio de Defensa. 
Misiones de la Unión Europea

\begin{tabular}{|c|c|c|c|c|c|}
\hline Misión & Lugar & Tipo & $\begin{array}{l}\text { Presu } \\
\text { puesto }\end{array}$ & nas & Perso \\
\hline \begin{tabular}{ll}
\multicolumn{3}{c|}{$1 .-$} \\
PRÓxIMA \\
(Misión de la \\
policía e la UE \\
en la & ex \\
república & \\
yugoslava & de \\
Macedonia. & \\
\end{tabular} & Macedo & Civil & $€ 15 \mathrm{M}$ & & 200 \\
\hline \begin{tabular}{lr}
\multicolumn{2}{|c|}{$2 .-$} \\
EUJUST \\
THEMIS \\
(Misión de la \\
UE en pro del \\
Estado & de \\
derecho & de \\
Georgia) & \\
\end{tabular} & Georgia & Civil & $€ 2.5 \mathrm{M}$ & & 10 \\
\hline $\begin{array}{l}\text { 3.- } \\
\text { MPUE (Misión } \\
\text { de policía de la } \\
\text { UE en Bosnia } \\
\text { y Herzegovina) } \\
\end{array}$ & $\begin{array}{c}\text { Bosnia } \\
\text { y Herzegovina }\end{array}$ & Civil & $\begin{array}{l}€ 38 \mathrm{M} \\
\text { anuales }\end{array}$ & 500 & $400-$ \\
\hline \begin{tabular}{ll}
\multicolumn{2}{c|}{$4 .-$} \\
EUPAT \\
(equipo policial \\
consultivo de \\
la UE en la \\
Antigua & \\
República & \\
yugoslava de \\
Macedonia) \\
\end{tabular} & nia Macedo & Civil & $€ 1.5 \mathrm{M}$ & & 30 \\
\hline \begin{tabular}{lr}
\multicolumn{2}{c|}{$5 .-$} \\
EUPOL \\
COPPS \\
(Misión r de \\
policía de la \\
UE para los \\
territorios \\
palestinos) \\
\end{tabular} & $\begin{array}{l}\text { Territori } \\
\text { os Palestinos }\end{array}$ & Civil & $\begin{array}{l}€ 6.1 \mathrm{M} \\
\text { anuales }\end{array}$ & & 33 \\
\hline \begin{tabular}{l}
\multicolumn{2}{|c|}{$6 .-$} \\
MAFUE- \\
RAFAH (Misión \\
de asistencia \\
fronteriza de la \\
UE para el
\end{tabular} & $\begin{array}{l}\text { Territori } \\
\text { os Palestinos }\end{array}$ & Civil & $€ 11.5$ & & 75 \\
\hline
\end{tabular}




\begin{tabular}{|c|c|c|c|c|}
\hline $\begin{array}{l}\text { paso fronterizo } \\
\text { de Rafah en } \\
\text { los territorios } \\
\text { palestinos) }\end{array}$ & & & & \\
\hline \begin{tabular}{lr}
\multicolumn{2}{c|}{$7 .-$} \\
EUPOL \\
KISHANA \\
(Misión & \\
policía de & de la \\
UE & en \\
Kishana) & \\
\end{tabular} & RDC & Civil & $\begin{array}{l}\qquad 4.4 \mathrm{M} \\
\text { anuales }\end{array}$ & 29 \\
\hline 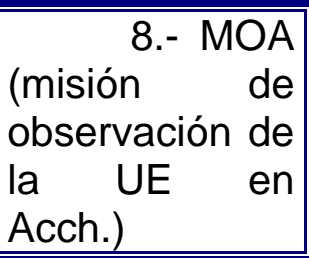 & Indones & Civil & $€ 15 \mathrm{M}$ & 200 \\
\hline \begin{tabular}{lr}
\multicolumn{2}{c|}{$9 .-$} \\
Misión \\
fronteriza & de la \\
UE & para \\
Moldova & y \\
Ucrania & \\
\end{tabular} & $\begin{array}{l}\text { Moldavi } \\
\text { a y Ucrania }\end{array}$ & Civil & $x_{2}$ & 120 \\
\hline $\begin{array}{c}10 .- \\
\text { CONCORDIA } \\
\end{array}$ & nia Macedo & Militar & $€ 6.2 \mathrm{M}$ & 600 \\
\hline $\begin{array}{l}\text { 11.- } \\
\text { ARTEMIS }\end{array}$ & $\begin{array}{l}\text { ca Repúbli } \\
\text { Democrática } \\
\text { del Congo }\end{array}$ & Militar & $€ 7 \mathrm{M}$ & 2000 \\
\hline \begin{tabular}{l}
\multicolumn{1}{c}{$12 .-$} \\
EUFOR \\
ALTHEA \\
\end{tabular} & $\begin{array}{r}\text { Bosnia } \\
\text { y Herzegovina }\end{array}$ & Militar & $€ 71.7$ & 6200 \\
\hline \begin{tabular}{lr}
\multicolumn{2}{c|}{ 13.- } \\
EUJUST LEX \\
(Misión \\
integrada de la \\
UE por & el \\
Estado & de \\
derecho & de \\
Iraq) & \\
\end{tabular} & Iraq & Civil & $€ 10 \mathrm{M}$ & $x$ \\
\hline \begin{tabular}{l}
\multicolumn{3}{c|}{$14 .-$} \\
AMIS II (Apoyo \\
de la UE a \\
AMIS II)
\end{tabular} & Sudán & Militar & $€ 4 M$ & 9 \\
\hline \begin{tabular}{l}
\multicolumn{2}{c|}{$15 .-$} \\
EUDEC RDC. \\
República
\end{tabular} & $\begin{array}{l}\text { Repúbli } \\
\text { ca } \\
\text { Democrática }\end{array}$ & Civil & $€ 1.6$ & $x$ \\
\hline
\end{tabular}




\begin{tabular}{|c|c|c|c|c|c|c|}
\hline $\begin{array}{l}\text { Democrática } \\
\text { del Congo }\end{array}$ & del Congo & & & & & \\
\hline \begin{tabular}{l}
\multicolumn{1}{c}{$16 .-$} \\
EUSEC RDC. \\
República \\
Democrática \\
del Congo
\end{tabular} & $\begin{array}{l}\text { Repúbli } \\
\text { ca } \\
\text { Democrática } \\
\text { del Congo }\end{array}$ & Militar & M & $€ 16.7$ & 450 & $400-$ \\
\hline $\begin{array}{l}17 .- \\
\text { NUV } \\
\text { NAVFOR } \\
\text { ATALANTA }\end{array}$ & Somali & Militar & & $€ 8.3 \mathrm{M}$ & & 1.200 \\
\hline \begin{tabular}{l}
\multicolumn{1}{c}{$18 .-$} \\
EUSSR \\
Guinea Bissau
\end{tabular} & 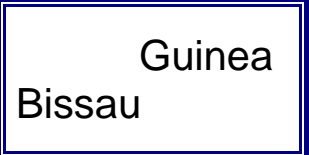 & Militar & & $€ 5.6 \mathrm{M}$ & & 33 \\
\hline $\begin{array}{c}19 .- \\
\text { EUFOR Chad }\end{array}$ & \begin{tabular}{c|} 
Chad \\
Centroafricana
\end{tabular} & Militar & $\mathrm{N}$ & $€ 119.6$ & & 3.700 \\
\hline
\end{tabular}

Fuente: Elaboración Propia con información del Consejo de la Unión Europea y de Unidad de Investigación sobre Seguridad y Cooperación Internacional (UNISCI).

En este sentido, en el Tratado de Lisboa de 2007, se estipulaba la creación de la nueva figura que llevaría a la PESD (Política Exterior de Seguridad y Defensa) a modificarse por la PESC (Política Exterior de Seguridad Común) y que desembocaría en la creación de un Servicio Europeo de Acción Exterior coordinado por la Alta Representante para Asuntos Exteriores y Política de Seguridad.

Respecto a la Estrategia Europea de Seguridad de 2003, "Una Europa Segura en un mundo mejor"19, la Unión hace una especial referencia en la cual las amenazas y desafíos son completamente diferentes en relación al tratamiento que se les daba en el pasado.

La Seguridad se había convertido con esta estrategia en lo que un país necesitaba como medida de desarrollo y las amenazas se convertían en menos visibles y menos previsibles. Incluso, la Unión se encontraba ante más de 30 conflictos abiertos, algunos en escalada y otros solo latentes. El 11-S, se convirtió en el hito que cambiaría el tratamiento de la seguridad tal cual la conocíamos.

Europa comenzó a notar que problemas como los de Cachemira, la región de los Grandes Lagos y la península de Corea tenían repercusiones directas en los intereses europeos, la descomposición del Estado, el abuso de poder y su falta de responsabilidad, así como la debilidad de sus instituciones se hacía cada vez más evidente y por tanto la inestabilidad de ciertos países le sumirían en breve tiempo en una crisis.

\footnotetext{
${ }^{19}$ (2003) Una Europa Segura en un mundo mejor. Estrategia Europea de Seguridad. Bruselas, 12 de diciembre.
} 
El caso de las revueltas árabes ha terminado en una guerra civil dolorosa y en la que pocos países europeos han deseado inmiscuirse en los asuntos internos de países como es el caso de Siria. La resolución del conflicto árabe-israelí, más diplomática para los europeos representa una prioridad. El proceso de Barcelona también es un compromiso de la Unión para evitar conflictos en la zona mediterránea

La OTAN y La OSCE son dos organizaciones que refuerzan el papel de la Unión en materia de prevención de conflictos y esto se ve reflejado en los instrumentos que a continuación se señalan.

Instrumentos de la Unión Europea en Prevención de Conflictos:

Ahora bien, los instrumentos de la Unión Europea para la prevención de conflictos y reforzados en Lisboa se centran en:

\section{Civiles por medio de:}

\section{*Comisión Europea.}

*De naturaleza económica.- Apoyo para la realización de Políticas económicas en el país que sufre el conflicto.

*Causas estructurales.- Apoyo al país en conflicto en materia de Estado de Derecho

Naturaleza civil.- Por ejemplo policía.

*A Largo Plazo.- Por ejemplo la Ayuda al Desarrollo

\section{*Consejo.}

*De naturaleza política.- Apoyo al país en conflicto en materia de democracia y derechos humanos.

*A Corto plazo.- Diálogo político.

*Actividades CIMI.-civiles y militares.- Lucha contra el crimen organizado, tráfico de drogas y lavado de dinero.

Con el Tratado de Lisboa, la Unión Europea se ve fortalecida en uno de sus instrumentos civiles para la prevención de conflictos, la ayuda al desarrollo, de la cual se hará cargo la Alta Representante. Está ayuda involucra a países como los ACP (África, Caribe y Pacífico), ayuda a la construcción de Documentos de Estrategia País y se centra especialmente en Acuerdos como el de Cotonú.

Otro instrumento a largo plazo se ve reflejado por medio del reforzamiento de las políticas comerciales de la Unión Europea hacia regiones específicas como América Latina y el Caribe, Asia Central, la Región del Golfo , el Mediterráneo y el Caúcaso.

En materia de Democracia y Derechos humanos, la Unión da apoyo para que los países constituyan sus directrices. También ofrece ayuda para la realización 
de gestiones y declaraciones, apoyo como observadores electorales entre otros.

Así mismo, la Unión Europea brinda asistencia a representantes especiales que promueven políticas e intereses, ellos son nombrados por el Consejo y apoyan a la Alta Representante en todas la tareas antes señaladas.

Por otro lado $\mathrm{ECHO}^{20}$, es la organización humanitaria de la Unión Europea para apoyar a las víctimas de conflictos fuera de la Unión. A través de ella se suscita ayuda de urgencia las 24 horas ya sea alimentaria, en materia de refugiados, entre otros.

Las medidas diplomáticas y en incremento después de la creación del Servicio Europeo de Acción Exterior (SEAE) se ven incrementadas y reforzadas, tanto, que los mismos miembros de la Comisión son partidarios de la implementación correcta y directa de las políticas comerciales, a largo y a corto plazo.

La Unión también posee un mecanismo de reacción rápida, el cuál está dividido en áreas de actuación, por ejemplo, asesoramiento de respuestas a crisis, gestión de crisis inminentes, reconciliación post- conflicto, reconciliación postcrisis y lucha contra el terrorismo.

Las misiones en las que participa la Unión se centran en la construcción de paz o peace building en inglés, además colabora en la consolidación de las instituciones de los países en transición post-conflicto. Una de las características más importantes es la ayuda en formación y funcionamiento de la policía, así como el asesoramiento legal y jurídico.

Los equipos civiles, auténtica novedad de hace a penas unos años, son expertos en todas las áreas, inician la valoración temprana de una situación de crisis y apoyan el establecimiento de una misión civil, apoyan tanto a nivel temporal como a una misión ya en marcha.

La Unión como impulsora de la integración en el mundo.

De acuerdo a la Comunicación relativa a la Comisión en materia de prevención de Conflictos $^{21}$, la Unión es un proyecto de paz, que ha dado magníficos resultados y ha respaldado la conciliación de la democracia y la prosperidad.

Los instrumentos de la Unión se pueden utilizar de manera directa o indirecta, predecir la evolución de los conflictos es una ardua tarea y por eso la Unión trata de proporcionar acciones de cooperación.

El Instrumento Europeo de Vecindad y Asociación (IEVA) es el instrumento financiero de la política europea de vecindad (PEV). Va dirigido a los países socios de la Política Europea de Vecindad y a Rusia, y propone cofinanciación

${ }^{20}$ European Commission Humanitaria Aid and Civil Protection. Más información en: http://ec.europa.eu/echo/index_en.htm

${ }^{21}$ (2001) Documento COM/2001/0211final*/ Comunicación de la Comisión relativa a la prevención de conflictos. 
para los procesos de fortalecimiento de la gobernanza y del desarrollo económico y social equitativo. Este instrumento poya también la cooperación transfronteriza e interregional, así como la integración económica progresiva a la Unión Europea (UE) de los países beneficiarios.

EI IEVA apoya, en particular:

Reformas políticas: instauración y adaptación de capacidades institucionales y administrativas, buena gobernanza, Estado de Derecho, respeto de los derechos humanos, participación de la sociedad civil, diálogo multicultural, y lucha contra el fraude, la corrupción, la delincuencia organizada y el terrorismo; reformas económicas: desarrollo económico, economía de mercado, intensificación del comercio y aproximación normativa con la UE en ámbitos de interés común y en la perspectiva de la integración económica progresiva al mercado interior; reformas sociales: integración, empleo, no discriminación y lucha contra la pobreza; cooperación sectorial, especialmente en los sectores que presentan un interés común: medio ambiente, desarrollo sostenible, energía, transporte, telecomunicaciones, sanidad, seguridad alimentaria, educación y formación, investigación e innovación; desarrollo regional y local, así como integración regional (regiones Euromediterránea y de Europa Oriental) y subregional; participación en los programas y agencias comunitarias. $^{22}$

La Unión Europea lleva a cabo acciones de cooperación exterior que pretenden apoyar la estabilidad de los terceros países y que busca utilizar la prevención antes que la acción posterior en el terreno. Por ello, las medidas financiadas por el Instrumento de Estabilidad deben contribuir a la elaboración y a la reacción ante las crisis de origen natural o humano, cuya innovación es sumamente importante, el mecanismo relativo a la gestión de crisis naturales así como a la rehabilitación de los países tras una crisis o una situación de inestabilidad, caracterizará a la Unión después de la entrada en vigor del Tratado de Lisboa.

El Instrumento de Estabilidad financia las acciones de cooperación al desarrollo y de cooperación financiera, económica y técnica que la Unión Europea (UE) lleva a cabo en asociación con terceros países. Las acciones pretenden:

restablecer la estabilidad en el caso de situaciones de emergencia, crisis o crisis incipiente, con el fin de aplicar de forma efectiva las políticas de desarrollo y de cooperación; reforzar la capacidad de preparación de los terceros países frente a las crisis y a las amenazas mundiales y transregionales. $^{23}$

Las capacidades militares de la UE, sobre todo las capacidades logísticas, completan la ayuda proporcionada en el marco de estos dos dispositivos. Es no

\footnotetext{
22 (2006) Instrumento Europeo de Vecindad y Asociación. http://europa.eu/legislation_summaries/external_relations/relations_with_third_countries/eastern

$\underset{23}{23}$ europe_and_central_asia/r17101_es.htm Instrumento $_{(2006)}$ de Estabilidad. http://europa.eu/legislation_summaries/foreign_and_security_policy/conflict_prevention/l14171_ es.htm
} 
obstante indispensable velar por que las capacidades militares utilizadas en el marco de una acción humanitaria mantengan su carácter civil e imparcial. La Comisión, que considera que es esencial preservar la neutralidad del «espacio humanitario», concede una gran importancia al respeto de las directrices de las Naciones Unidas sobre la utilización de los recursos militares y la protección civil en el marco de las operaciones de ayuda humanitaria vinculadas o no a conflictos.

Por tanto, como ya se ha visto, la Unión tiene muchos instrumentos y mecanismos que facilitan y estabilizan su entrada en las zonas de conflicto, pero que con Lisboa, las actuaciones de la Unión Europea se presuponen más ágiles y ponen a prueba la coherencia y visibilidad que tanto se suele señalar.

\section{3.- La Cumbre de Lisboa y el Nuevo concepto estratégico de la OTAN; repercusiones en la Política Exterior de la Unión Europea.}

La OTAN ha supuesto para la Unión un impulso en prevención de conflictos, gracias a la organización, Europa ha podido incursionar en el ámbito militar y mejorar su respuesta rápida ante cualquier etapa del conflicto, es por ello que se ha puesto de manifiesto en la Cumbre de Lisboa, una mayor participación con Afganistán mediante una asociación duradera y una declaración conjunta del Consejo de OTAN- Rusia.

El desarrollo de una dimensión de seguridad y defensa en la UE, el incremento de países miembros y asociados, la guerra de Georgia, el regreso de Rusia al concierto de potencias, las amenazas de proliferación de armas de destrucción masiva o los nuevos riesgos derivados de la globalización, representan cambios que se han sucedido desde 1999 y que hacían necesario reorientar el planteamiento de la Alianza, preservando los fundamentos de defensa de las libertades y los valores democráticos que, hoy como entonces, constituyen su razón de ser. ${ }^{24}$

Tanto la Unión Europea, al igual que ocurre en la OTAN, formalmente expresan los nuevos riesgos en esta Cumbre, tales como la proliferación de armas de destrucción masiva, misiles balísticos, armas nucleares, terrorismo, la inestabilidad más allá de las fronteras de actuación OTAN y Unión Europea, los ciberataques, los ataques sobre las vías de comunicación, la guerra electrónica, tecnologías que limitan el acceso al espacio, ataques al medio ambiente entre otras.

El enfoque integral de la OTAN, también se ve respaldado por la Unión, ya que conjuga medios políticos, civiles y militares. Es certero decir que 21 de los 27 miembros de la Unión Europea son miembros OTAN y por tanto la Unión es considerada un socio único y esencial. Antes, con la Unión Europea Occidental (UEO), Europa denotaba un cierto rechazo a la Organización Atlántica, sin embargo en 2002, con los acuerdos de Berlín Plus se sentaron las bases para la cooperación entre OTAN y la UE en el ámbito de la gestión de crisis.

${ }^{24}$ (2011) Conferencia del SEGENPOL en el Ciclo de Conferencias Generales CESEDEN. Ministerio de Defensa, Secretaría General de Política de Defensa. Conferencias SEGENPOL. Centro Superior de Estudios de la Defensa Nacional, 19 de enero. 
Los nuevos instrumentos civiles y militares convirtieron a la Unión en parte esencial para impedir o prevenir una crisis, restablecer la paz y reconstruir las instituciones tras un conflicto. La flexibilidad de la que la OTAN carecía, mostró a la Unión como certera ante los ojos del mundo.

Es indudable que tanto la Unión, como la OTAN afrontan retos similares y vínculos en diversas áreas, por eso sus relaciones se han estrechado desde 1999.

La cooperación y apoyo mutuo ha hecho que se traten minimamente de solapar y duplicar en sus operaciones, tratando de maximizar la eficacia de ambas.

En esta Cumbre, la Unión Europea y la OTAN, comparten las lecciones aprendidas y mejoran sus iniciativas, siendo más realistas para los conflictos que existen en la actualidad, así como la mejora de instrumentos como el transporte estratégico y táctico.

En este sentido, la OTAN y la Unión refuerzan el enfoque integral para disponer de una capacidad civil y militar.

Se debe insistir que en este foro se recogen los principales puntos en materia de seguridad que también le conciernen a la Unión y se debe valorar el papel tan predominante que la Unión Europea juega potenciado por el Tratado de Lisboa.

\section{4.- Conclusiones}

El Tratado aún no ha dado precisiones completas de cómo se debe orientar la Política Exterior de la Unión Europea en materia de Prevención de Conflictos, pero se siguen llevando a cabo enormes esfuerzos sobre la marcha.

El mecanismo de la Cooperación Estructurada Permanente se desarrolla para permitir que cualquiera de los 27 Estados miembros pueda participar en este mecanismo, incluyendo la exclusividad al exigir requisitos para la incorporación y permanencia en este instrumento. Por tanto, se suele decir que también la Unión se ha decantado por una tendencia más política, y otra más técnica. Evidentemente, a efectos operativos, cuanto más exigentes sean los requisitos de entrada, y sobre todo, los compromisos de mejora de las capacidades para garantizar la permanencia, más útil resultará al propósito de la incorporación de nuevos países a la Unión.

La visión más técnica es preferible dentro de la Política Exterior de Seguridad Común (PESC), la prioridad de esta tendencia es esencial pues hay que tener en consideración que la CEP es un instrumento recogido en el Tratado de Lisboa, y que su aplicación -y la concreción de los requisitos- está sometido al Consejo por lo que es probable que se adquiera una solución y visión ante todo de compromiso. ${ }^{25}$

25 (2011) La Cooperación Estructurada Permanente en el Marco de la Unión Europea. (CESCEDEN), Centro Superior de Estudios de la Defensa Nacional. Ministerio de Defensa. 
La eficacia de la UE en la prevención de conflictos podría beneficiarse de una mejor combinación de los esfuerzos y los recursos de las relaciones exteriores de la Comunidad y de la cooperación intergubernamental en cuestiones de política exterior.

Con el apoyo de los Parlamentos nacionales y del Parlamento Europeo se puede hacer más para estrechar la asociación con sus Estados miembros, las Naciones Unidas y otras organizaciones y países, así como con la sociedad civil, para prevenir conflictos, fomentar la reconciliación y fortalecer los procesos de paz. ${ }^{26}$

La Unión Europea, concluye que la Comisión considera que las ventajas de la acción preventiva quedan demostradas y se muestra decidida a utilizar los instrumentos comunitarios de modo más eficaz y coordinado. Se propone desplegar esfuerzos en el ámbito de:

* La integración de los objetivos de paz, democracia y estabilidad política y social en los programas de ayuda;

* La consideración de los indicadores relativos a la exclusión política y étnica, la marginalización social y regional y el deterioro medioambiental;

* La aportación de un valor añadido a las iniciativas internacionales en materia de cuestiones transversales de conflicto potencial;

* La utilización acertada de otros medios tales como el comercio, la política social, etc.;

*El desarrollo de los planteamientos e instrumentos nuevos. ${ }^{27}$

En este sentido, la Unión ha hecho grandes esfuerzos, pero es necesario un compromiso aún mayor por medio del Tratado de Lisboa. La Alta Representante debe también valorar que la prevención siempre requiere menor gasto que la actuación en el terreno postconflicto.

El fenómeno de la democratización europea, tal y como hemos comprobado en el Tratado de Lisboa avanza de manera firme en el modelo. Las novedades introducidas en este texto afectan de forma positiva a la posición de los ciudadanos ante la UE, recogiendo las pretensiones de la Declaración de Laeken sobre el futuro de la Unión Europea que establecía que ésta debía llegar a ser "más democrática, transparente y eficaz".

En cuanto al nuevo papel de los Parlamentos nacionales, el cómo y con qué intensidad sean utilizados los poderes que les otorga el Tratado de Lisboa a los Parlamentos nacionales será la clave del éxito de las medidas impulsar el control de subsidiaridad, mismo que refuerza la legitimidad democrática de la UE.

\footnotetext{
${ }^{26}$ (2006) Reunión parlamentaria, El futuro de Europa: de la reflexión a la acción. El papel de la Unión Europea en la Prevención de Conflictos, 4-5 de diciembre, Bruselas, Bélgica.

27 (2006), Prevención de Conflictos de la Unión Europea. http://europa.eu/legislation_summaries/foreign_and_security_policy/conflict_prevention/r12700_ es.htm
} 
Finalmente decir que la Comisión afirma que la capacidad de actuación de la Unión está relacionada con tres ejes rectores y fundamentales: una definición clara de los objetivos, una capacidad de actuación y, sobre todo, una voluntad política de actuación.

\section{5.- Bibliografía.}

\section{Libros}

ALDECOA LUZÁRRAGA, F. GUINEA LLORENTE, M. (2010) "La Europa que viene: El Tratado de Lisboa", Marcial Pons, Madrid. España.

GUTIERREZ ESPADA, C. CERVELL HORTAL, M. J. (2010) La adaptación al Tratado de Lisboa (2007) del sistema institucional decisorio de la UE, su acción exterior y su personalidad jurídica, Editorial Comares, Murcia. España.

GARZÓN CLARIANA, G. (2009) "Democracia y Estado de Derecho en la puesta en marcha del Tratado de Lisboa", en Francisco Aldecoa Luzárraga, Luis Norberto González Alonso y Mónica Guzmán Zapater (eds.): La presidencia española de la Unión Europea en 2010 : propuestas para una agenda ambiciosa, Madrid, Asociación Española de Profesores de Derecho Internacional y Relaciones Internacionales, pp. 33-44.

SCHIMMELFENNING F. (2009) The Normative Origins of Democracy in the European Union: Towards a Transformationalist Theory of Democratization (Los orígenes normativos de la democracia en la Unión Europea: transformación de la Teoría de la Democratización), Challenges to Democracy in the 21st Century. Zurich.

GUINEA LLORENTE, M. (2008) "De Roma I a Roma II: la aportación del Tratado -Constitución al modelo político de la integración europea", en Francisco Aldecoa Luzárraga, José Manuel Sobrino Heredia, Luis Norberto González Alonso, Antonio Pastor Palomar, Joaquim Forner y Mónica Herranz Ballesteros (Coords.): Los tratados de roma en su cincuenta aniversario, Marcial Pons, Madrid, pp.43- 70.

GIL-ROBLES DELGADO, J. M. (2007) "Tratado de Lisboa: Un paso adelante en la evolución del sistema institucional europeo, Revista de las Cortes Generales", Madrid, España. pp. 10-37.

KAELBLE, H. (2005) Caminos hacia la democracia los déficit democráticos de la Unión Europea, Biblioteca nueva, Madrid.

\section{Revistas}

DE AYALA, J. E. (2010) Política Exterior, "Lisboa por fin. El tratado abre una nueva era en la UE", no 133, enero/febrero.

FERNÁNDEZ-ARIAS, C. (2009), Política Exterior, Hacia una diplomacia común. El Servicio Europeo de Acción Exterior, nº 133, enero/febrero. 


\section{Textos oficiales}

La Cooperación Estructurada Permanente en el Marco de la Unión Europea. (2011) (CESCEDEN), Centro Superior de Estudios de la Defensa Nacional. Ministerio de Defensa.

20 años de España en la Unión Europea, Ministerio de Asuntos Exteriores y Cooperación.

http://www.maec.es/es/menuppal/espanayue/EspanaenEuropa/Paginas/etxesp anaeuropa.aspx

Posibles escenarios de actuación de los Battlegroups de la Unión Europea. (2007) Centro Superior de Estudios de la Defensa Nacional. Ministerio de Defensa.

Prevención de Conflictos de la Unión Europea (2006). http://europa.eu/legislation_summaries/foreign_and_security_policy/conflict_pre vention/r12700_es.htm

Instrumento Europeo de Vecindad y Asociación. (2006) http://europa.eu/legislation_summaries/external_relations/relations_with_third_c ountries/eastern_europe_and_central_asia/r17101_es.htm

Instrumento de Estabilidad.

http://europa.eu/legislation_summaries/foreign_and_security_policy/conflict_pre vention/l14171

/2001/0211final*/ Comunicación de la Comisión relativa a la prevención de conflictos.

La Unión Europea en ampliación y las Naciones Unidas: Hacer que el multilateralismo importe. (2004) Publicado por la Unión Europea aprobado por la TROIKA y los Estados Miembros en Nueva York - Capítulo 5.

Una Europa Segura en un mundo mejor. Estrategia Europea de Seguridad. (2003) Bruselas, 12 de diciembre.

European Commission Humanitaria Aid and Civil Protection. (2001) http://ec.europa.eu/echo/index_en.htm

Documento COM

Consejo Europeo de Niza, texto completo en: http://www.europarl.europa.eu/summits/nice1_es.htm\#III

Consulta pública sobre la Iniciativa Ciudadana Europea.

http://ec.europa.eu/dgs/secretariat_general/citizens_initiative/index_es.htm

United Nations: 2008 Status of Contributions to the Regular Budget, International Tribunals, Peacekeeping Operations and Capital Master Plan. 


\section{Congresos}

Conferencia del SEGENPOL en el Ciclo de Conferencias Generales CESEDEN. (2011) Ministerio de Defensa, Secretaría General de Política de Defensa. Conferencias SEGENPOL. Centro Superior de Estudios de la Defensa Nacional, 19 de enero.

CARNERO, C. (2010), Congreso "Los grandes retos de la Presidencia Española", 24 de Febrero. Madrid, España.

LUENGO, F. (2009) Encuentro Internacional Complutense. Ciencia y Sociedad. "El papel de Europa en el Escenario Internacional: Visiones desde los países del Centro y Este del Continente", organizado por el Instituto Complutense de Estudios Internacionales, el 25 y 26 de Marzo.

Reunión parlamentaria, El futuro de Europa: de la reflexión a la acción. (2006) El papel de la Unión Europea en la Prevención de Conflictos, 4-5 de diciembre, Bruselas, Bélgica. 